\title{
Charles Augustin Sainte-Beuve, Vigny
}

\section{Esther Pinon}

\section{(2) OpenEdition}

\section{Journals}

\section{Édition électronique}

URL : https://journals.openedition.org/studifrancesi/3150

DOI : 10.4000/studifrancesi.3150

ISSN : 2427-5856

\section{Éditeur}

Rosenberg \& Sellier

\section{Édition imprimée}

Date de publication : 1 juillet 2013

Pagination : 472-473

ISSN : 0039-2944

\section{Référence électronique}

Esther Pinon, «Charles Augustin Sainte-Beuve, Vigny », Studi Francesi [En ligne], 170 (LVII | II) | 2013,

mis en ligne le 30 novembre 2015, consulté le 02 février 2023. URL : http://journals.openedition.org/ studifrancesi/3150; DOI : https://doi.org/10.4000/studifrancesi.3150

\section{Ce document a été généré automatiquement le 2 février 2023.}

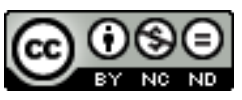

Creative Commons - Attribution - Pas d'Utilisation Commerciale - Pas de Modification 4.0 International - CC BY-NC-ND 4.0

https://creativecommons.org/licenses/by-nc-nd/4.0/ 


\section{Charles Augustin Sainte-Beuve, Vigny}

\section{Esther Pinon}

\section{RÉFÉRENCE}

CHARLES AUGUSTIN SAINTE-BEUVE, Vigny, textes présentés et annotés par Michel BRIX, Paris, Éditions Kimé, 2013, pp. 167.

1 La susceptibilité littéraire de Vigny est presque aussi légendaire que le tranchant de la plume critique de Sainte-Beuve. De l'examen des œuvres de l'auteur de Chatterton par le portraitiste des Lundis ne pouvaient donc émaner que des relations tendues, voire conflictuelles. Ce sont elles que Michel Brix remet au jour en réunissant les écrits que, pendant près de quarante ans, Sainte-Beuve a consacrés à Vigny.

2 L'ensemble donne à lire un véritable dialogue, car, à l'exception du compte rendu très défavorable de Cinq-Mars rédigé par Sainte-Beuve pour «Le Globe» en juillet 1826 c'est-à-dire avant que les deux auteurs ne fassent connaissance au sein du Cénacle hugolien - les articles du critique se construisent tous en fonction des réactions, passées ou à venir, de Vigny, soit qu'ils anticipent sur l'accueil que doit leur réserver le poète, soit qu'ils reviennent sur ses réponses aux écrits précédents. Le principe, dialogique par nature, de la critique est donc ici dédoublé: Sainte-Beuve répond à l'homme autant qu'il examine l'œuvre. Ce dispositif particulier de l'écriture permet d'entrevoir la naissance d'une amitié littéraire, puis de percevoir son délitement: aux vers enthousiastes des Consolations, aux articles élogieux consacrés à «Éloa» et à Chatterton succède un portrait plus mesuré, publié à l'occasion de la parution de Servitude et grandeur militaires. Celui-ci suscite l'ire de Vigny, qui appelle elle-même un vif plaidoyer de Sainte-Beuve pour sa propre critique, joint à l'article initial lorsque le texte est intégré aux Portraits contemporains en 1869. Le compte rendu de la réception de Vigny à l'Académie française, le portrait publié dans la «Revue des deux mondes» en 
1864 et plus encore les impitoyables «Notes et pensées» durcissent le trait d'une critique dans laquelle l'agacement se fait de plus en plus perceptible.

L'introduction de Michel Brix, ainsi que les notes qui accompagnent chaque texte de Sainte-Beuve, retracent très précisément les circonstances de cette inéluctable mésentente, en dévoilant notamment des stratégies éditoriales parfois complexes, destinées à déjouer la méfiance de Vigny. Toutefois le différend qui éloigne progressivement les deux auteurs, et que traduisent les réserves formulées par SainteBeuve, est loin de répondre uniquement à des motifs personnels. Il est avant tout d'ordre littéraire, comme le suggère Michel Brix en établissant un parallèle entre la brouille de Sainte-Beuve avec Hugo et celle qui l'oppose à Vigny. Les textes réunis dans le volume sont ainsi considérés comme autant de témoignages des tensions qui traversent le Cénacle, et plus largement le romantisme français. Michel Brix esquisse ainsi les oppositions qui ont pu sourdre autour des questions spirituelles et de leur prise en charge par la littérature. Bien que rapides, les pages qu'il consacre à ce sujet dans son introduction sont sans doute celles qui donnent véritablement sens, intérêt et profondeur à l'ensemble que constituent les textes ici regroupés. 